\title{
Pobreza e Política Social: a implementação de programas complementares do Programa Bolsa Família
}

\author{
Poverty and Social Policy: the implementation \\ of complementary programs for the Bolsa Família Program
}

Cláudia Roberta Bocca Santos ${ }^{1}$

Rosana Magalhães ${ }^{2}$

${ }^{1}$ Instituto de Nutrição, Universidade do Estado do Rio de Janeiro (UERJ). Rua São Francisco Xavier 524/ 12, Maracanã. 20559-900 Rio de Janeiro RJ. claubocca@gmail.com ${ }^{2}$ Departamento de Ciências Sociais, Escola Nacional de Saúde Pública (ENSP), Fundação Oswaldo Cruz (Fiocruz).
Abstract The Bolsa Familia Program involves the transfer of income and the implementation of complementary programs to foster human capital development and empower the beneficiaries. To analyze the implementation of complementary programs in Manguinhos, Rio de Janeiro, a review of documents and secondary data was conducted, focus groups of beneficiaries studied and semi-structured interviews were staged with governmental, nongovernmental stakeholders and beneficiaries. The design, coverage and evaluation of the complementary programs have been weak, and beneficiaries were even unaware of vocational training courses. The program administrators acknowledged the failings and the fact that the courses offered by Próximo Passo are not adapted to local demand, even though they were conceived as a vocational training strategy aimed at creating construction jobs in the Growth Acceleration Program and the tourist industry in the city. Considering that the social inclusion perspective is linked to access to public policies, the supply and follow-up of these activities by government agencies and civil society organizations are essential for the effectiveness of the fight against poverty and hunger, aimed at contributing to the so-called "exit routes" from the Bolsa Familia Program.

Key words Poverty, Public policy, Social policy, Conditional cash transfer programs, Intersectorality
Resumo O Programa Bolsa Família articula a transferência de renda à implementação de programas complementares, a fim de promover o desenvolvimento de capital humano e a autonomização dos beneficiários. Para analisar a implementação dos programas complementares em Manguinhos, Rio de Janeiro, realizamos consultas documentais; grupos focais com beneficiários; entrevistas semiestruturadas com atores governamentais, não-governamentais e beneficiários, além da coleta de dados secundários. O desenho, a cobertura e a avaliação dos programas complementares mostraram-se frágeis. Os beneficiários desconheciam cursos de qualificação profissional. Os gestores reconheceram a debilidade das ações e destacaram que os cursos do Próximo Passo não se adéquam à demanda local, ainda que pensados como estratégia de capacitação voltada às obras do Programa de Aceleração do Crescimento e à vocação turística da cidade do Rio de Janeiro. Considerando que a perspectiva de inclusão social está atrelada ao acesso às políticas públicas, a oferta e o acompanhamento destas ações pelas esferas governamentais e organizações civis constituem um eixo crucial para o combate à pobreza e à fome, contribuindo para as chamadas "portas de saída" do Programa Bolsa Família.

Palavras-chave Pobreza, Politica pública, Política social, Programa de Transferência Condicionada de Renda, Intersetorialidade 


\section{Introdução}

Instituído em 2003 pela Medida Provisória no ${ }^{\circ} 32^{1}$, o Programa Bolsa Família (PBF) é a principal estratégia brasileira de combate à pobreza. Visa a articulação da transferência direta de renda ao cumprimento de condicionalidades pelas famílias beneficiárias e à oferta de programas complementares, como geração de emprego e de renda, cursos profissionalizantes, apoio às iniciativas de economia solidária, entre outros. É voltado ao público inscrito no Cadastramento Único para Programas Sociais do Governo Federal (CADÚNICO), desde que caracterizado em situação de extrema pobreza ou de pobreza, segundo os níveis de renda familiar per capita ${ }^{2}$.

O PBF é constantemente alvo de debates no meio acadêmico, que remetem principalmente ao valor do benefício, à focalização do Programa, ao acompanhamento das condicionalidades e à dicotomia direito social e exigência de contrapartidas $s^{3-6}$. Desde a criação do PBF, vários dispositivos legais explicitam a necessidade do adensamento de políticas públicas voltadas às famílias beneficiárias, dispondo também sobre a alocação de recursos e sobre as atribuições dos entes federados enquanto articuladores com órgãos e com instituições, governamentais ou não-governamentais, para o fomento à implementação de programas complementares ${ }^{1,7-18}$. No entanto, investigações em torno da implementação e do alcance dos mesmos ainda são escassas.

Compreendendo a pobreza como um fenômeno complexo e multifatorial, torna-se essencial a articulação da transferência do benefício monetário a outras políticas, emergenciais e estruturantes, a fim de evitar a reatualização de práticas assistencialistas. A perspectiva de inclusão social incorporada ao PBF busca ultrapassar a distribuição de benefícios monetários, avançando em direção a estratégias voltadas à emancipação das famílias pobres. Diante deste contexto, o objetivo deste artigo foi compreender o processo de implementação dos programas complementares em um contexto de vulnerabilidade social como Manguinhos.

\section{Abordagem metodológica}

Esta pesquisa, realizada entre 2008 e 2010, foi aprovada pelo Comitê de Ética em Pesquisa da Escola Nacional de Saúde Sérgio Arouca (ENSP). Compôs um projeto desenvolvido pela ENSP e pelo Centro Colaborador de Alimentação e Nutrição da Região Sudeste, ambos da Fundação Oswaldo
Cruz (Fiocruz), intitulado "Estudo da Implementação do Programa Bolsa Família no Estado do Rio de Janeiro - A experiência de Manguinhos".

A pesquisa estudou a implementação do $\mathrm{PBF}$ a nível local, com o recorte analítico dos programas complementares. Weiss ${ }^{19}$ propõe que a avaliação de programas sociais seja feita baseada na teoria do programa que subjaz a intervenção e não em um modelo de avaliação previamente normatizado. Outros autores corroboram sua visão, como Chen ${ }^{20}$, Shaw e Crompton ${ }^{21}$ e Paw$\operatorname{son}^{22}$. Partindo desta contribuição, a teoria do PBF nos leva a crer que a perspectiva de autonomização das famílias beneficiárias se dará por meio do acesso destas aos serviços sociais básicos e aos programas complementares, o que é corroborado pela comunidade científica.

Foi adotado o estudo de caso, tal qual proposto por Denis e Champagne ${ }^{23}$, Contandriopoulos et al..$^{24} \mathrm{e} \mathrm{Yin}{ }^{25}$. A potência explicativa do estudo de caso se apóia na profundidade da análise e não no número de unidades analíticas, não visando a generalização dos resultados ${ }^{23,25}$. A opção foi pelo estudo de caso único incorporado ${ }^{25}$, utilizando dados secundários, consultas documentais, grupos focais com beneficiários, além de entrevistas semiestruturadas com beneficiários, atores governamentais e não-governamentais.

As consultas documentais se basearam em Leis, Portarias, Medidas Provisórias, Decretos, Instruções Normativas e Operacionais, além de documentos oficiais do PBF. A revisão de literatura usou livros, revistas acadêmicas, jornais, homepages e áudios de eventos científicos disponíveis em bibliotecas virtuais. Para a análise do contexto local, foram utilizados estudos realizados na região de Manguinhos; notícias sobre a região; o Censo Demográfico do Instituto Brasileiro de Geografia e Estatística de 200026; a homepage do Instituto Municipal de Urbanismo Pereira $\operatorname{Passos}^{27}$; o Guia de Equipamentos e Iniciativas Sociais de Manguinhos de 200128; o Censo Domiciliar do Complexo de Manguinhos ${ }^{29}$ e o banco de dados do projeto "Ações Intersetoriais em Promoção da Saúde”, da ENSP/Fiocruz ${ }^{30}$.

A identificação dos atores envolvidos na implementação do PBF se deu por visitas à homepage da Secretaria Municipal de Assistência Social do Rio de Janeiro (SMAS-RJ) e do contato com informantes-chave. Foram realizadas sete entrevistas com atores governamentais da SMAS-RJ no próprio local de atuação dos mesmos, sendo selecionados aqueles cuja função fosse a gestão e/ou a implementação do PBF, tanto no nível local quanto no central, em especial dos progra- 
mas complementares, além do acompanhamento das famílias beneficiárias. Quanto aos atores não-governamentais, foram selecionados aqueles que tivessem relação com a implementação dos programas complementares no contexto local e pudessem influenciar o acesso das famílias a programas sociais como, por exemplo, representantes de organizações sociais e atores-chave do movimento social de Manguinhos, sendo realizadas quatro entrevistas. Foram também adotadas as contribuições do Guia de Equipamentos e Iniciativas Sociais de Manguinhos de $2001^{28}$ e do banco de dados do projeto "Ações Intersetoriais em Promoção da Saúde" 30 .

O caminho utilizado para a identificação das famílias beneficiárias do PBF residentes em Manguinhos se deu mediante o contato com informantes-chave. Oito entrevistas foram realizadas, mas apenas cinco foram incorporadas neste trabalho, em função da recusa na assinatura do Termo de Consentimento Livre e Esclarecido. Foram realizados três grupos focais com beneficiários - segundo as orientações disponíveis em Neto et al. $^{31}$ e Minayo ${ }^{32}$ - que buscaram garantir a maior pluralidade possível de locais de residência e de arranjos familiares, incluindo famílias monoparentais, extensas ou aquelas formadas por casal e filhos.

A análise do material ocorreu segundo as categorias analíticas: articulação do PBF com as demais políticas públicas desenvolvidas no município do Rio de Janeiro; processo de implementação dos programas complementares no município do Rio de Janeiro; articulação da gestão municipal com a sociedade civil organizada com vistas à implementação dos programas complementares; e acesso das famílias beneficiárias aos programas complementares ofertados.

\section{Resultados e discussão}

Manguinhos abriga comunidades com desigual grau de acesso aos equipamentos públicos e às iniciativas sociais, marcadas ainda por expressivos contrastes socioeconômicos. Há uma pulverização de organizações e de lideranças comunitárias na região envolvidas na discussão das demandas locais. Trata-se de um contexto palco de vultosos investimentos das três esferas de governo, traduzidos no Programa de Aceleração do Crescimento (PAC), que traz grandes expectativas em torno da reconfiguração deste espaço ${ }^{28,27,33,34}$. A análise do contexto local revela que Manguinhos constitui-se num rico cenário para análise da im- plementação de um programa como o PBF, que prevê articulação com a sociedade civil organizada para a oferta de programas complementares.

Segundo o Censo Domiciliar de Manguinhos ${ }^{29}$, estima-se que existam 31.432 habitantes na região. No entanto, essa estimativa deve ser analisada com cautela, visto que o Censo Domiciliar não foi plenamente realizado. De acordo com os gestores entrevistados, é difícil precisar o número de famílias cadastradas e beneficiárias do PBF em Manguinhos. Primeiramente, tal fato decorre da divisão do território, que ficou sob responsabilidade de duas Coordenadorias de Assistência Social. Além disso, dados incompletos de endereços residenciais das famílias e erros de digitação corroboram ao problema. O Censo Domiciliar de Manguinhos indica que $10,1 \%$ das residências visitadas recebem o benefício ${ }^{29}$.

\section{Articulação do Programa Bolsa Família com as demais políticas públicas desenvolvidas no município do Rio de Janeiro}

A fim de atender ao objetivo oficial de promover o desenvolvimento de capital humano e estimular a autonomização das famílias beneficiárias, diversos autores afirmam que o PBF deveria funcionar como porta de entrada das famílias beneficiárias para outros programas sociais ${ }^{3,435-40}$. A intersetorialidade no PBF é identificada em função do próprio desenho do Programa, que estabelece a exigência do cumprimento de condicionalidades nas áreas de educação, saúde e assistência social, envolvendo na gestão do PBF suas respectivas Secretarias.

Os gestores entrevistados informaram que a relação entre essas Secretarias se dá de maneira muito mais próxima, especialmente em função do grupo intergestor, considerado uma estratégia para efetivar a intersetorialidade no PBF. No entanto, Coelho ${ }^{41}$ revelou que tais reuniões não ocorriam com regularidade desde 2007, embora previstas em norma legal ${ }^{42}$, que também estabelece a composição do grupo intergestor, que deveria incluir outros setores além daqueles diretamente envolvidos no acompanhamento das condicionalidades. O CADÚNICO foi apontado pelos gestores como um instrumento de focalização das famílias pobres do município nos programas sociais e, nesse sentido, de convergência de políticas públicas às famílias em vulnerabilidade social na cidade.

No entanto, gestores do nível local revelaram que a articulação com a saúde e a educação é 
ainda frágil, muitas vezes dependendo exclusivamente da iniciativa individual de algum profissional. Para aquelas políticas e programas não alocados nas Secretarias Municipais responsáveis pelo acompanhamento das condicionalidades, os entrevistados revelaram que tal articulação se dá de maneira incipiente, ou não ocorre:

[...] Eu acho que nem a nivel central existe isso. [...] Eu não vejo isso na ponta acontecer, o que existe é uma relação de boa vizinhança. [...] Se existisse efetivamente uma articulação, o que a gente chama de intersetorialidade entre a saúde, educação, assistência e habitação na área, você projetava conjuntamente. Não acontece isso. Cada um no seu quadrado, sem conversar. Às vezes você conheceu o assistente social do posto por acaso numa reunião, aí eu faço uma articulação, mas isso não é institucional (Gestor 3).

Tais percepções corroboram o que vem sendo descrito pela literatura: apesar do objetivo oficial, o PBF ainda falha em dar efetivas respostas intra e intersetoriais à problemática da pobreza e da exclusão social, ou seja, a articulação entre a transferência de renda e a participação de beneficiários em outros programas estruturantes ainda é insatisfatória, limitando as perspectivas de emancipação sustentada das famílias beneficiárias ${ }^{37,39,43}$.

\section{Processo de implementação dos programas complementares no município do Rio de Janeiro}

A maioria dos programas complementares ofertados são federais e gerenciados por Ministérios setoriais ${ }^{2}$. Há pouco envolvimento das esferas estadual e municipal na oferta destes programas, embora na Portaria $n^{\circ} 246^{15}$ estejam previstos compromissos dos gestores do Programa nos três níveis de governo. Entre eles, estão o de promover a articulação e a integração do $\mathrm{PBF}$ com programas complementares executados no âmbito federal e o estabelecimento de parcerias com órgãos e instituições governamentais e nãogovernamentais, nas três esferas, para a oferta de programas complementares ${ }^{2,15}$. Lindert et al. ${ }^{44}$ afirmam que os programas complementares exigem colaboração intersetorial e intergovernamental para sua efetiva implementação.

Os gestores reconheceram que a implementação de programas complementares ainda é débil em Manguinhos. Um dos citados foi o Próximo Passo, que busca promover qualificação e inserção profissional, com oferta de cursos na área da construção civil e de turismo. A definição dos cursos que seriam ofertados pelo Próximo Passo foi resultado de uma análise das potencialidades dos municípios. No caso do Rio de Janeiro, foram consideradas, pelo Governo Federal, a ampliação do campo de trabalho em função das obras do PAC e da vocação turística da cidade.

Pesquisas desenvolvidas pelo Instituto Brasileiro de Análises Sociais e Econômicas ${ }^{43}$, por Silva et al. ${ }^{39}$ e por Magalhães et al. ${ }^{37}$ revelam que este não é um problema exclusivo do município do Rio de Janeiro. Ainda é pouco expressiva a integração do PBF com outras políticas públicas, em função da baixa implementação dos programas complementares e do pouco conhecimento das famílias acerca das ações existentes. A maioria dos titulares do benefício assegura que o PBF não contribuiu para o acesso a cursos de educação formal ou de alfabetização. Além disso, as políticas de inserção produtiva são as menos ofertadas no país: apenas 13\% passaram a frequentar curso de educação formal e somente $16 \%$ começaram a participar de programas de geração de renda ${ }^{43}$. Nesta perspectiva, Silva et al. ${ }^{39}$ afirmam que a rede de serviços públicos de todos os municípios do Maranhão é insuficiente para atender às necessidades das famílias. Os encaminhamentos às ações complementares apenas ocorrem em casos de demandas individuais específicas, e não sistematicamente. Magalhães et al. ${ }^{37}$ também apontam a inexistência de programas complementares nos municípios de Duque de Caxias e São Francisco de Itabapoana, ambos localizados no estado do Rio de Janeiro. Sabe-se que a implementação dos programas complementares no território nacional dependerá das múltiplas diversidades regionais e distintas capacidades financeiras e gerenciais dos municípios, conforme apontado por Silva et al. ${ }^{39}$. Beneficiários residentes em municípios menores e mais pobres, que não dispõem de recursos financeiros e de capacidade técnica para implementação de programas complementares, tendem a ser penalizados nesse sentido.

A literatura acadêmica destaca que não há, a nível federal, uma indução financeira específica para a implementação dos programas complementares, a exemplo do que ocorre para o acompanhamento das condicionalidades e para qualificação do CADÚNICO ${ }^{3,439,40}$. Na realidade, embora os recursos advindos do Índice de Gestão Descentralizada (IGD) possam ser utilizados para tal fim, não há penalidade prevista aos entes federados que não os implementarem, tal qual ocorre com as condicionalidades. A Resolução Municipal n ${ }^{\circ} 47 / 2006^{14}$ estabelece que metade dos 
recursos advindos do IGD devem ser utilizados para a implementação dos programas complementares no município do Rio de Janeiro, entretanto, os gestores entrevistados apontaram:

A gente utiliza esse IGD para investir na atuação desses técnicos com as famílias. A gente está fazendo uma mega compra de computador agora, porque nossos computadores estão obsoletos [...]. Estamos comprando mesas, móveis, cadeiras para os Centros de Referência da Assistência Social... (Gestor 6).

A aplicação do recurso do IGD na cidade reafirma o que foi apontado pela pesquisa realizada pela Secretaria Nacional de Renda e Cidadania ${ }^{45}$, que revela que tais recursos foram utilizados, prioritariamente, como investimento em infraestrutura da gestão do PBF e do CADÚNICO, com a aquisição de computadores $(67,8 \%$ dos municípios) e de material de consumo (62,8\%).

A despeito do diagnóstico prévio das vocações locais, os gestores destacaram que muitos programas complementares oferecidos pelo Governo Federal não se adéquam à realidade de Manguinhos, em função do perfil socioeconômico das famílias e das vulnerabilidades que apresentam.

[...] O que está acontecendo é construção civil, eletricista, azulejista [referindo-se aos cursos do Próximo Passo]. Na comunidade, as pessoas já estão expert em fazer isso, pelo histórico do processo de autoconstrução, de trabalhar em obra. [...] Não tem muita adesão, [...] não tem interesse nisso. [...] Então a não adesão está pelo deslocamento do que é ofertado pela demanda real, há uma incongruência aí (Gestor 3).

Os atores não-governamentais também questionaram a adequação da oferta dos programas complementares ao público ao qual se destinam e indicaram a necessidade de considerar o que emerge como demanda da população local. Para Silva et al. ${ }^{39}$, desconsiderar as especificidades regionais e municipais é um obstáculo ao PBF. No caso da Renda Mínima de Inserção francesa, segundo Astier ${ }^{46}$, a inserção no mercado de trabalho se dá com base na análise das potencialidades e das fragilidades individuais dos beneficiários, como forma de personalizar a estratégia adotada para a emancipação da família e valorizar habilidades prévias. Os programas Chile Solidário e Tekoporã também estabelecem, baseados na análise individualizada de cada família pelos guias familiares, as contrapartidas a serem exigidas e o caminho a ser percorrido rumo à emancipação dos beneficiários ${ }^{47,48}$. No caso do PBF, essa premissa se perde, visto que a implementação dos programas complementares, em especial do Próximo Passo, foi top-down e não reconheceu as demandas do contexto local.

Um dos atores não-governamentais, envolvido no movimento social local, alertou para a forma como o PBF propõe a inserção das famílias beneficiárias, questionando a precariedade da inclusão no mercado de trabalho e o alcance das ações de qualificação profissional:

É a inclusão no mercado de forma subalterna [...]. Esses cursos aqui acontecem à balde [...]. É algo interessante constituir equipes de trabalho que possam prestar serviços. Agora, não é pra todo mundo que vai fazer o curso [...]. Camareira e arrumadeira, todo mundo faz isso (Ator não-governamental 1).

Nesse sentido, Castel $^{49}$ traz importante contribuição, distinguindo as políticas de integração daquelas de inserção. As primeiras buscariam o equilíbrio, a "homogeinização da sociedade", com o intuito de promover a todos o acesso aos serviços públicos. Já as políticas de inserção são aquelas que atuam reparando os efeitos do disfuncionamento social, sem alterar suas causas: "obedecem à lógica da discriminação positiva: definem com precisão a clientela e as zonas singulares do espaço social e desenvolvem estratégias específicas para elas" ${ }^{49}$.

Nesse sentido, ao propor cursos de qualificação profissional aos beneficiários como estratégia para promover inclusão social, a teoria do Programa nos revela que o desenho do PBF compreende que faltam às famílias conhecimentos para que estas possam se inserir no mercado de trabalho e se emancipar do Programa. No entanto, há que se considerar que a oferta de serviços sociais básicos e de programas complementares, embora essenciais para a autonomização das famílias, não podem ser as únicas estratégias utilizadas para concretização deste objetivo. Para Silva et al. ${ }^{50}$, os programas sociais historicamente desenvolvidos no Brasil baseiam-se em políticas compensatórias e desarticuladas das de desenvolvimento econômico. Lindert et al. ${ }^{44}$ afirmam que as estratégias para emancipação dependem não apenas de incentivos para melhorar a empregabilidade dos beneficiários, ou seja, aumentar sua qualificação profissional, também é necessário uma economia forte, que produza empregos e oportunidades geradoras de renda. No caso do Brasil, os autores ressaltam que, em algumas situações, as famílias se beneficiariam de uma mistura de abordagens devido às múltiplas necessidades e vulnerabilidades. 


\section{Articulação da gestão municipal com a sociedade civil organizada com vistas à implementação dos programas complementares}

A escolha de quais instituições seriam as executoras do Próximo Passo no município do Rio de Janeiro se deu por edital público do Ministério do Trabalho e Emprego. Foram identificadas pelos gestores duas que ganharam a licitação. Embora não localizadas em Manguinhos, ambas atendem beneficiários desta e de outras localidades no município. Cabe ressaltar que, apesar da implementação do PBF no Rio de Janeiro ter se iniciado em 2004, o convênio para a oferta do Próximo Passo somente se deu em janeiro de 2009 e começou efetivamente a ser implementado apenas em maio de 2009.

Durante a realização da pesquisa, foi identificada uma terceira organização, que também oferece cursos de construção civil do Próximo Passo para o município do Rio de Janeiro, Duque de Caxias, Mesquita e Magé. No entanto, nenhum gestor citou a entidade durante as entrevistas. Os atores não-governamentais envolvidos no movimento social local desconheciam a natureza, a abrangência e o perfil da oferta dos programas complementares, embora os gestores tenham afirmado que há articulação com a sociedade civil organizada para a implementação dos cursos. $\mathrm{Na}$ realidade, a visão acerca da articulação com a sociedade civil organizada no caso de Manguinhos se limita ao convite feito às lideranças comunitárias e às iniciativas sociais para a divulgação dos programas que serão implementados, para a indicação de possíveis participantes dos cursos ou na contratação de mão de obra local e, no caso das instituições aprovadas no edital público, para a oferta dos programas. Não há um planejamento conjunto das atividades que serão oferecidas, o que pode provocar a incongruência entre o programa que está sendo oferecido e a necessidade que o contexto local apresenta.

O mapeamento de equipamentos públicos e iniciativas sociais e as entrevistas com famílias beneficiárias e com lideranças comunitárias não identificaram projetos e programas sociais voltados prioritariamente aos beneficiários do $\mathrm{PBF}$, a não ser nos equipamentos públicos de excelência da política de Assistência Social. Lideranças comunitárias e beneficiárias do PBF também não identificaram nenhuma atividade oferecida por Associações de Moradores ou organizações sociais em Manguinhos que priorizem as famílias beneficiárias do PBF.
Foi unânime entre os gestores locais e do nível central a sensação de que os beneficiários do PBF temem perder o benefício ao participar do Próximo Passo. No entanto, por mais que se afirme que o vínculo formal de trabalho não se traduz, necessariamente, em desligamento do PBF, o medo por parte das famílias é real e tem embasamento. O critério de elegibilidade das famílias para o Programa é a renda familiar per capita autorreferida. Conforme destacam Silva et al. ${ }^{39}$, a renda autodeclarada como único critério para definir quais serão as famílias beneficiárias acaba restringindo o PBF àquelas famílias cujos membros estão inseridos no mercado informal de trabalho, já que estes podem omitir a renda auferida, ao contrário dos trabalhadores do setor formal. Neste sentido, embora o mercado informal represente uma desproteção social ao trabalhador, pode ser mais interessante para algumas famílias manterem-se no trabalho informal e serem beneficiárias do PBF, que contarem apenas com os recursos advindos de sua remuneração do trabalho. Os precarizados vínculos trabalhistas atuais também podem dificultar a efetiva inserção dos beneficiários no mercado de trabalho. Para Lindert et al. ${ }^{44}$, quanto maior a relação direta entre aumento de salário e redução correspondente das transferências diretas de renda, maior é o incentivo para que os beneficiários reduzam seus esforços de trabalho, a fim de evitar perder os benefícios, já que os recebem por estarem abaixo da linha de pobreza considerada pelo Programa. Ou seja, na visão dos autores, os beneficiários do PBF podem renunciar oportunidades de ganhos com a redução de seu esforço de trabalho para evitar a perda de benefícios, que são geralmente mais estáveis do que o salário.

Considerando a perspectiva de Becker ${ }^{51}$ de que a implementação de programas e políticas públicas deve considerar e incorporar as especificidades do contexto local, há que se considerar, na perspectiva de conferir efetividade a este eixo do PBF, as potencialidades de Manguinhos e suas contribuições para a implementação dos programas complementares. Atkinson et al. ${ }^{52}$ alertam para o estímulo da capacidade das comunidades para lidarem com seus problemas, com proposição de construção, com a própria comunidade, de soluções locais para problemas locais. Envolver moradores e lideranças comunitárias locais no processo de planejamento, desenvolvimento e avaliação destas ações pode contribuir para o desenvolvimento comunitário local e para o desenvolvimento de capital humano. 
Acesso das famílias beneficiárias aos programas complementares ofertados

Os relatos das beneficiárias entrevistadas apontaram para a pluralidade na oferta de projetos na região, empreendidos pela sociedade civil organizada. Muitos deles são pouco sustentáveis e executam ações pontuais, sem grande impacto no cenário local e sem conseguir favorecer a inclusão no mercado de trabalho.

Eu acho que não deveria ter o Bolsa Família. [...] Eu acho que o ideal seria ele oferecer emprego para as pessoas trabalharem [...]. Eu acho que ele deveria estar oferecendo cursos, qualificando a pessoa e estar oferecendo emprego para ela estar trabalhando. [...] Aqui em Manguinhos tem bastante curso, nada a ver com Bolsa Família. Mas acabou o curso, acabou [...]. Você se vira, vai procurar emprego [...] (Beneficiária 1).

Os grupos focais e as entrevistas realizadas com os titulares do benefício corroboram ao já descrito na literatura ${ }^{43}$ : as famílias desconheciam, por exemplo, a oferta de cursos de qualificação prioritariamente voltados aos beneficiários e afirmaram que as oportunidades que surgem não são vinculadas ao PBF, além da baixa oferta de vagas. O mesmo ocorre em relação a ações de alfabetização, de capacitação profissional, de geração de emprego e de renda e de desenvolvimento comunitário e territorial. Quando questionadas sobre o que poderia melhorar no PBF, indicaram que deveriam ser oferecidos cursos para todas as idades, em especial informática para os adolescentes, com uma clara preocupação em relação à inserção dos jovens no tráfico de drogas. Outra demanda importante apontada pelas beneficiárias foi a necessidade de vagas em creches públicas.

Não foi possível conseguir através das entrevistas e do contato com a gestão do Programa o número de beneficiários que estão participando do Próximo Passo, pois não havia clareza entre os gestores e os responsáveis pelas instituições que o ofertam sobre o número de alunos que residiam em Manguinhos.

A invisibilidade dos programas complementares para as famílias em Manguinhos dificulta sua inserção e, consequentemente, a emancipação sustentada, afetando as "portas de saída" do Programa. Silva et al. ${ }^{39}$ identificaram, em relação às ações voltadas à autonomização das famílias beneficiárias, que a oferta de programas complementares é limitada nos municípios do Maranhão e Piauí e a busca por programas se dá por iniciativa individual que parte das famílias. Mesmo naqueles locais em que há a oferta, esses autores destacam que a autonomização ainda não é garantida, visto que a inserção no mercado de trabalho é limitada. Com base na visão de Draibe ${ }^{53}$, o processo de autonomização das famílias beneficiárias só deixará de ser utopia com o investimento contínuo nas pessoas. $\operatorname{Codes}^{54}$ defende que o combate à pobreza remete ao desenvolvimento de capacidades de uma pessoa, por meio de ações individuais e coletivas, que possam proporcionar condições de superação dos ciclos de pobreza.

Outra questão importante a ser ressaltada é que não há um acompanhamento das famílias beneficiárias após o desligamento do PBF. Villa ${ }^{55}$ defende a premissa de que as condições de saída de Programas de Transferência de Renda focalizados não devem ser unicamente o perfil socioeconômico dos beneficiários, deve considerar a probabilidade destes em manterem seu nível de consumo sem o benefício monetário. O autor destaca que grande parte dos Programas não apresenta regras claras sobre as "portas de saída" dos beneficiários, sendo que, em alguns, as condições de saída são iguais aos critérios de elegibilidade. Na visão dele, geralmente os beneficiários são desligados dos programas quando deixam de apresentar as condições que os permitiram ser selecionados para o recebimento do benefício, sem se considerar a possibilidade de deterioração das condições de vida após seu desligamento do programa.

\section{Conclusão}

A análise do processo de implementação dos programas complementares a partir da experiência local de Manguinhos nos permitiu identificar alguns desafios postos ao PBF. A falta de informações a respeito das famílias beneficiárias e, mais especificamente, daquelas que participam dos programas complementares ofertados torna difícil focalizar as famílias mais vulneráveis e realizar seu acompanhamento longitudinal. A articulação da transferência direta de renda às demais políticas públicas limita-se àqueles setores responsáveis pelo acompanhamento das condicionalidades. Os gestores reconheceram que há baixa oferta de programas complementares e que os já existentes foram implementados de maneira top down, sem considerar as demandas que emanam do contexto local, a despeito do diagnóstico prévio das potencialidades do município. A participação da sociedade civil organizada na implementação dos programas complemen- 
tares não pressupõe o planejamento conjunto das ações a serem ofertadas. Lideranças comunitárias e atores não-governamentais desconhecem a oferta dos programas complementares, o que, aliado ao desconhecimento das famílias beneficiárias, pode limitar o alcance destas ações. Nesse sentido, em Manguinhos, o desenho, a cobertura e a avaliação destas iniciativas mostram-se frágeis. Ao desconsiderar o contexto local e não reconhecer as demandas e especificidades das famílias beneficiárias, dificilmente os programas complementares conseguirão alcançar seus objetivos de emancipação sustentada e de autonomização das famílias beneficiárias. Portanto, permanece sendo um desafio ao PBF buscar maior aproximação com a realidade local, evitando ações verticalizadas e favorecendo o diálogo com ações da sociedade civil organizada.

\section{Colaboradores}

CRB Santos participou na coleta e análise dos dados e na redação do manuscrito. R Magalhães trabalhou na concepção e no delineamento da pesquisa, na análise e na interpretação dos dados e na revisão crítica da redação final.

\section{Agradecimentos}

Agradecimento especial à equipe de pesquisa do projeto "Efetividade das Ações Intersetoriais em promoção da saúde: a experiência de Manguinhos, RJ", coordenado pela Dra. Regina Cele de Andrade Bodstein, pela acolhida e pelas valiosas discussões. 


\section{Referências}

1. Brasil. Medida Provisória ${ }^{\circ} 132$ de 20 de outubro de 2003. Cria o Programa Bolsa Família e dá outras providências. Diário Oficial da União 2003; 20 out.

2. Brasil. Ministério do Desenvolvimento Social. Bolsa Família [site na Internet]. [acessado 2010 jan 13]. Disponível em: http://www.mds.gov.br/bolsafamilia

3. Monnerat GL, Senna MCM, Schottz V, Magalhães $\mathrm{R}$, Burlandy L. Do direito incondicional à condicionalidade do direito: as contrapartidas do Programa Bolsa Família. Cien Saude Colet 2007; 12(6):1453-1462.

4. Senna MCM, Burlandy L, Monnerat GL, Schottz V, Magalhães R. Programa Bolsa Família: nova institucionalidade no campo da política social brasileira? Katálysis 2007; 10(1):86-94.

5. Zimmermann CR. Desafios à implantação do direito à alimentação no Brasil. Democracia Viva 2008; 39:14-17.

6. Ferreira MN. Programas de Transferência Condicionada de Renda e Acesso aos Serviços de Saúde: um estudo da experiência do Programa Bolsa Família em Manguinhos, RJ [dissertação]. Rio de Janeiro: Fiocruz; 2009.

7. Brasil. Lei $\mathrm{n}^{\circ} 10.836$ de 09 de janeiro de 2004. Cria o Programa Bolsa Família e dá outras providências. Diário Oficial da União 2004; 09 jan.

8. Brasil. Decreto $n^{0} 5.209$ de 17 de setembro de 2004 . Regulamenta a Lei $\mathrm{n}^{\circ} 10.836$, de 9 de janeiro de 2004, que cria o Programa Bolsa Família, e dá outras providências. Diário Oficial da União 2004; 17 set.

9. Brasil. Portaria Interministerial MEC/MDS nº 3.789 de 17 de novembro de 2004. Dispõe sobre as atribuições e normas para a oferta e o monitoramento das ações de educação relativas às condicionalidades das famílias beneficiárias do Programa Bolsa Família dos Programas Remanescentes. Diário Oficial da União 2004; 17 nov.

10. Brasil. Portaria Interministerial MS/MDS no 2.509 de 18 de novembro de 2004. Dispõe sobre as atribuições e normas para a oferta e o monitoramento das ações de saúde relativas às condicionalidades das famílias beneficiárias do Programa Bolsa Família. Diário Oficial da União 2004; 18 nov.

11. Brasil. Portaria ${ }^{\circ} 148$ de 27 de abril de 2006. Estabelece normas, critérios e procedimentos para o apoio à gestão do Programa Bolsa Família e do Cadastro Único de Programas Sociais do Governo Federal no âmbito dos municípios, e cria o Índice de Gestão Descentralizada do Programa. Diário Oficial da União 2006; 27 abr.

12. Brasil. Portaria $\mathrm{n}^{\circ} 256$ de 18 de julho de 2006. Altera dispositivos da Portaria $n^{\circ} 148$, de 27 de abril de 2006. Diário Oficial da União 2006; 18 jul.

13. Brasil. Portaria $\mathrm{n}^{\circ} 40$ de 25 de janeiro de 2007. Altera a Portaria MDS/GM n ${ }^{\circ} 148$, de 27 de abril de 2006. Diário Oficial da União 2007; 25 jan.

14. Prefeitura Municipal do Rio de Janeiro. Resolução $\mathrm{n}^{\circ} 47$ de 15 de maio de 2006. Diário Oficial do Município do Rio de Janeiro 2006; 15 maio.
15. Brasil. Portaria $\mathrm{n}^{\circ} 246$ de 20 de maio de 2005. Aprova os instrumentos necessários à formalização da adesão dos municípios ao Programa Bolsa Família, à designação dos gestores municipais do Programa e à informação sobre sua instância local de controle social, e define o procedimento de adesão dos entes locais ao referido Programa. Diário Oficial da União 2005; 20 maio.

16. Brasil. Instrução Normativa $n^{\circ} 1$ de 20 de maio de 2005. Divulga orientações aos municípios, Estados e Distrito Federal para constituição de instância de controle social do Programa Bolsa Família (PBF) e para o desenvolvimento de suas atividades. Diário Oficial da União 2005; 20 maio.

17. Brasil. Instrução Operacional $n^{\circ} 9$ de 5 de agosto de 2005. Divulga instruções sobre os procedimentos operacionais necessários à formalização da adesão dos municípios ao Programa Bolsa Família e ao Cadastro Único de Programas Sociais, orienta os gestores e técnicos sobre a designação do gestor municipal do Bolsa Família e a formalização da Instância de Controle Social do Programa, e especifica a documentação a ser anexada para fins de comprovação das medidas adotadas. Diário Oficial da União 2005; 5 ago.

18. Brasil. Portaria $n^{\circ} 350$ de 03 de outubro de 2007. Dispõe sobre a celebração do Pacto de Aprimoramento da Gestão dos Estados e do Distrito Federal no contexto do Sistema Único de Assistência Social - SUAS, do Programa Bolsa Família e do Cadastro Único. Diário Oficial da União 2007; 03 out.

19. Weiss $\mathrm{CH}$. Nothing as practical as a good theory: exploring theory-based evaluation for Comprehensive Community Initiatives for Children and Families. In: Connell JP, Kubich AC, Schorr L, Weiss CH, organizadores. New Approaches to evaluating community initiatives. Concepts, Methods and Contexts. Washington, DC: Aspen Institute; 1995. p. 65-92.

20. Chen HT. Theory-Driven Evaluations. Newbury Park: Sage; 1990.

21. Shaw I, Crompton A. Theory, like mist on spectables, obscures vision. Evaluation 2003; 9(2):192-204.

22. Pawson R. Evidence-based policy: in search of a method. Evaluation 2002; 8(2):157-181.

23. Denis J, Champagne F. Análise da implantação. In: Hartz ZMA. Avaliação em saúde: dos modelos conceituais à prática na análise da implantação de programas. Rio de Janeiro: Fiocruz; 1997. p. 49-88.

24. Contandriopoulos A, Champagne F, Denis J, Pineault R. A avaliação na área da saúde: conceitos e métodos. In: Hartz ZMA. Avaliação em saúde: dos modelos conceituais à prática na análise da implantação de programas. Rio de Janeiro: Fiocruz; 1997. p. 29-47.

25. Yin RK. Estudo de caso: planejamento e métodos. $3^{\mathrm{a}}$ ed. Porto Alegre: Bookman; 2005.

26. Instituto Brasileiro de Geografia e Estatística (IBGE). Censo Demográfico. [site na Internet] [acessado 2010 jan 13]. Disponível em: http://www.ibge.gov.br

27. Instituto Municipal de Urbanismo Pereira Passos. Armazém de Dados. [site na Internet] [acessado 2008 set 2]. Disponível em: http://www.rio.rj.gov.br/ipp/ 
28. Bodstein R, Zancan L, Estrada DD. Guia de equipamentos e iniciativas sociais. Rio de Janeiro: Fiocruz; 2001.

29. Governo do Estado do Rio de Janeiro. $6^{0}$ Relatório Parcial do Censo Domiciliar de Manguinhos - Rio de Janeiro. Rio de Janeiro; 2009.

30. Bodstein R, Magalhães R, Ramos CL, Marcondes WB, Coelho AVAG, Bocca CR, Ferreira MN, Souza RM. Guia de equipamentos e iniciativas sociais de Manguinhos, 2009 - 2010. No prelo 2011.

31. Neto OC. O trabalho de campo como descoberta e criação. In: Minayo MCS. Pesquisa Social: teoria, método e criatividade. Petrópolis: Editora Vozes; 1993. p. 51-66.

32. Minayo MCS. O desafio do conhecimento: pesquisa qualitativa em saúde. 10 a ed. São Paulo: Hucitec; 2007.

33. Fernandes TM, Costa RGR. Histórias de Pessoas e Lugares - Memórias das comunidades de Manguinhos. Rio de Janeiro: Editora Fiocruz; 2009.

34. Zancan L, Bodstein R, Marcondes WB. Promoção da Saúde como caminho para o desenvolvimento local. A experiência em Manguinhos - RJ. Rio de Janeiro: Abrasco. Fiocruz; 2002.

35. Silva MOS. O Bolsa Família: problematizando questões centrais na política de transferência de renda no Brasil. Cien Saude Colet 2007; 12(6):1429-1439.

36. Viana AL. Programa Bolsa Família. Mimeo. No prelo 2004.

37. Magalhães R, Burlandy L, Senna MCM. Desigualdades sociais, saúde e bem-estar: oportunidades e problemas no horizonte de políticas públicas transversais. Cien Saude Colet 2007; 12(6):1415-1421.

38. Linhares F. Bolsa Família: um novo arranjo para os Programas de Transferência de Renda no Brasil [dissertação]. Niterói: Universidade Federal Fluminense; 2005.

39. Silva MOS, Lima AJ, Ferreira MDM, Silva MRF, Lima VFSA. O Bolsa Família no enfrentamento à pobreza no Maranhão e Piauí. São Paulo, Teresina: Cortez, Editora Gráfica da UFPI; 2008.

40. Monnerat GL. Transferência condicionada de renda, saúde e intersetorialidade: lições do Programa Bolsa Família [tese]. Rio de Janeiro: Escola Nacional de Saúde Pública Sérgio Arouca; 2009.

41. Coelho AVAG. A construção da Intersetorialidade no Programa Bolsa Família em Manguinhos, no Rio de Janeiro [dissertação]. Rio de Janeiro: Escola Nacional de Saúde Pública Sérgio Arouca; 2009.

42. Prefeitura Municipal do Rio de Janeiro. Decreto $n^{\circ}$ 24.702 de 08 de outubro de 2004. Cria Grupo Intergestor para os fins que menciona e dá outras providências. Diário Oficial do Município do Rio de Janeiro 2004; 08 out.

43. Instituto Brasileiro de Análises Sociais e Econômicas (Ibase). Repercussões do Programa Bolsa Família na Segurança Alimentar e Nutricional das famílias beneficiadas. Rio de Janeiro: Ibase; 2008.
44. Lindert K, Linder A, Hobbs J, Brière B. The Nuts and Bolts of Brazil's Bolsa Família Program: Implementing Conditional Cash Transfers in a Descentralized Context. Discussion Paper 2007; 709:1-145.

45. Brasil. Ministério do Desenvolvimento Social e Combate à Fome. Análise da Pesquisa sobre recursos do Índice de Gestão Descentralizada. Brasília: MDS; 2007.

46. Astier I. Le contrat d'insertion. Une façon de payer de sa personne? Politix 1996; 9(34):99-113.

47. Fonseca AMM, Viana ALA. Direito à saúde, atenção básica e transferências condicionadas de renda na América Latina. Cien Saude Colet 2007; 12(6):15051512.

48. Soares FV, Britto T. Dores de Crescimento: Os Principais Desafios dos Novos Programas de Transferência Condicional de Renda na América Latina. One Pagers Centro Internacional de Pobreza 2008; 44:1-2.

49. Castel R. As metamorfoses da questão social. Uma crônica do salário. $7^{\mathrm{a}}$ ed. Petrópolis: Editora Vozes; 2008.

50. Silva MOS, Yazbek MC, Giovanni, G. A política social brasileira no século XXI. A prevalência dos programas de transferência de renda. $2^{\mathrm{a}}$ ed. São Paulo: Cortez Editora; 2006.

51. Becker HS. Segredos e truques da pesquisa. Rio de Janeiro: Jorge Zahar Editor; 2007.

52. Atkinson R, Willis P. [Community Capacity Building - A Practical Guide] [site na Internet] [acessado 2008 maio 12]. Disponível em: http://www.chs. ubc.ca/archives/files/Community\%20CapacityBuilding\%20A\%20Practical $\% 20$ Guide.pdf

53. Draibe SM. Desenvolvimento humano e bem-estar social: orientações e estratégias de política social. Caderno do Núcleo de Estudos de Políticas Públicas/ UNICAMP 2005; 72:1-10

54. Codes ALM. A trajetória do pensamento científico sobre pobreza: em direção a uma visão complexa Texto para discussão do Instituto de Pesquisa Econômica Aplicada 2008; 1332:7-29.

55. Villa JM. ¿Qué familias están en condiciones de salir del programa Familias en Acción? International Poverty Centre Evaluation Note 2008; 4:1-23.

Artigo apresentado em 13/04/2011

Aprovado em 19/04/2011

Versão final apresentada em 02/05/2011 